\title{
BMJ Open Smoking and serum vitamin D in older Chinese people: cross-sectional analysis based on the Guangzhou Biobank Cohort Study
}

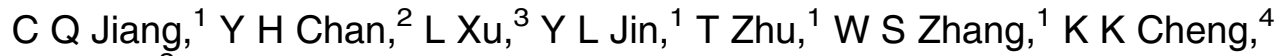 \\ $\mathrm{T} \mathrm{H}$ Lam $^{2}$
}

To cite: Jiang $C Q$, Chan $\mathrm{YH}$, $\mathrm{Xu} \mathrm{L}$, et al. Smoking and serum vitamin $D$ in older Chinese people: crosssectional analysis based on the Guangzhou Biobank Cohort Study. BMJ Open 2016;6:e010946. doi:10.1136/bmjopen-2015010946

- Prepublication history for this paper is available online. To view these files please visit the journal online (http://dx.doi.org/10.1136/ bmjopen-2015-010946).

Received 22 December 2015 Revised 14 April 2016 Accepted 3 May 2016

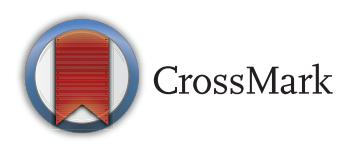

${ }^{1}$ Guangzhou No 12 Hospital, Guangzhou, China

${ }^{2}$ Division of Cardiology, Department of Medicine, Queen Mary Hospital, the University of Hong Kong, Hong Kong, China

${ }^{3}$ School of Public Health, the University of Hong Kong, Hong Kong, China ${ }^{4}$ Institute of Applied Health Research, University of Birmingham, Birmingham, UK

Correspondence to

$\operatorname{Dr} \mathrm{L} \mathrm{Xu}$;

linxu@hku.hk

\section{ABSTRACT}

Objective: Studies on serum vitamin $D$ in smokers showed conflicting results. We examined the association of smoking status with serum vitamin $D$ in older Chinese men, taking advantage of a communitybased sample with natural exposure to vitamin $D$.

Design: Cross-sectional study based on the Guangzhou Biobank Cohort Study (GBCS).

Setting: Community-based sample from the Guangzhou Biobank Cohort Study.

Participants: 612 male participants aged 50+years recruited from 2009 to 2011.

Results: The mean (SD) of vitamin D concentration was 58.3 (17.2), 57.0 (15.0) and 54.7 (15.4) nmol/L for never, former and current smokers, respectively. Adjusted for multiple confounders, vitamin D decreased from never to former, then to current smokers ( $P$ for trend 0.02). Compared to never smokers, current smokers had lower serum concentrations of vitamin $D$, and the concentrations decreased with the increasing number of cigarettes per day $(-3.11(95 \% \mathrm{Cl}-9.05$ to 2.82$),-3.29$ ( -8.3 to 1.72 ) and $-4.61(-8.89$ to -0.33$)$ for $1-9,10-19$ and $20+$ cigarettes per day, respectively; $p$ for trend 0.01 ), duration of smoking $(-1.39$ (-6.09 to 3.30$)$ and $-5.39(-9.42$ to -1.35$)$ for $1-39$ and 40 +years, respectively; $p$ for trend 0.008 ) as well as pack-years $(-2.89(-6.78$ to 1.01$)$ and $-5.58(-10.48$ to -0.67$)$ for 1-39 and 40+pack-years, respectively; $p$ for trend 0.009 ). Longer duration of quitting smoking was associated with higher vitamin $\mathrm{D}$ than was current smoking ( $P$ for trend 0.04).

Conclusions: Current smokers had lower vitamin D than never smokers, and the association showed a dose-response pattern.

\section{INTRODUCTION}

Lower serum levels of 25-hydroxyvitamin D (vitamin D) have been linked to a number of chronic diseases, such as fractures, ${ }^{1}$ diabetes ${ }^{2}$ and cardiovascular disease. ${ }^{3}$ The factors that may influence serum vitamin $\mathrm{D}$ concentration include skin type, body mass index, season

\section{Strengths and limitations of this study}

- The association of smoking with serum vitamin D was mixed.

- Most, but not all, studies reported lower serum vitamin $D$ in current smokers than in never smokers, and few studies examined the doseresponse association between smoking patterns and serum vitamin $D$.

- Taking advantage of a sample selected from the Guangzhou Biobank Cohort Study with natural exposure to vitamin $\mathrm{D}$, and the detailed assessed smoking habit, we could investigate the association of smoking with serum vitamin $D$ level more clearly.

and vitamin D ingested from foods or supplements. Other lifestyles that may influence serum vitamin D concentrations have not been well examined. Specifically, the association of smoking with serum vitamin D concentrations was unclear. Most of the recent studies reported lower serum vitamin $\mathrm{D}$ in current smokers than in never smokers. ${ }^{4-8}$ However, results from the Troms $\varnothing$ study showed the opposite-that current smokers had higher levels of serum vitamin $D$ than never smokers, in a sample of 6932 participants, and also in a subsample of $107(50 \%$ current smokers) participants. ${ }^{9}$ One possible explanation is that, in the West, smokers tend to smoke outside their home or office and thus may have higher sunlight exposure and subsequently lead to higher vitamin D concentrations. In Western countries, it is culturally inappropriate to smoke indoors, since the harms of secondhand smoke were established a few decades ago. Thus the influence of smoking on vitamin $\mathrm{D}$, if any, may be confounded by sunlight exposure during outdoor smoking. In China, most of the cities did not have indoor public-place smoking 
bans until very recently, and smoking in indoor places was quite acceptable. Guangzhou, one of the largest economically developed cities in China, did not adopt any legislation on indoor public place smoking ban until 2010. Moreover, very few, if any, older Chinese people use vitamin D or multivitamin supplements. Taking advantage of a sample selected from the Guangzhou Biobank Cohort Study (GBCS) without vitamin D supplementation, we could investigate the association of smoking with serum vitamin D level more clearly.

\section{METHODS}

The GBCS is a three-way collaboration among the Guangzhou No 12 Hospital, and the Universities of Birmingham and Hong Kong. Details of the setting and participant recruitment have been described elsewhere. ${ }^{10}$ From September 2003 to January 2008, 30430 permanent Guangzhou residents aged 50 years or above were recruited and attended a half-day detailed assessment session, which included a structured interview and a physical examination. Within our sample, the participants had fairly similar levels of chronic diseases such as diabetes and hypertension to nationally representative samples of urban Chinese. ${ }^{10}$ All GBCS participants were invited to return during March 2008-December 2012, for a follow-up examination. The methods and some results based on the follow-up data have been published elsewhere. ${ }^{11} 12$

The present study included 612 unselected men who returned for follow-up at the second examination, from 2009 to 2011, and had serum vitamin D measured. Physical examination included an interview on lifestyle, family and personal medical history, and measurement of weight, height, waist circumference, blood pressure, fasting plasma glucose, lipids and inflammatory markers. We collected detailed information on physical activity, using the Chinese version of the International Physical Activity Questionnaire (IPAQ). The validity and reliability of this questionnaire was assessed in 224 participants during a 7-day interval, and the results showed adequate test-retest reliability (intraclass correlation coefficient $=0.89) .{ }^{13}$ Participants were asked to recall the amount of time during the past week spent on physical activity, including vigorous activity such as heavy lifting, digging, aerobics or fast bicycling and moderate activity such as carrying light loads, bicycling at a regular pace or doubles tennis and walking. Frequency of and average amount of time per day spent on exercise were noted. A metabolic equivalent value (MET) was assigned to each type of activity according to accepted standards (see http://www.ipaq.ki.se), where 1 MET is a resting metabolic rate obtained during quiet sitting. MET value is 3.3 for walking, four for moderate activity and eight for vigorous activity. Participants were classified as either physically active, moderately active or inactive, according to the IPAQ. Physically active was defined as having vigorous activity at least 3 days a week, achieving at least 1500 MET minutes per week or activity on 7 days of the week achieving at least 3000 MET minutes per week. Moderately active was defined as having vigorous activity at least 3 days a week, achieving 480 METs, or at least 5 days of any combination of walking, moderate or vigorous activities achieving at least 600 METs. Those who did not meet the criteria for active or moderately active were considered to be physically inactive.

\section{Exposures}

Well-trained interviewers collected smoking data, using a standardised questionnaire. Smoking was defined as having had smoked at least one cigarette per day or seven cigarettes per week for at least half a year. 'Current smoker' was defined by answering 'yes' to the question: 'Do you smoke cigarettes now?'. 'Former smoker' was defined as 'used to smoke but not smoking currently'. ${ }^{14}{ }^{15}$ Information on duration of quitting smoking (years) was also collected. Reliability of the questionnaire was tested at baseline and the result was satisfactory. $\kappa$ Values were 0.88 and 0.96 for the two questions about smoking status. ${ }^{14}$ Several papers on smoking from GBCS have been published, suggesting that the smoking data should be reliable. ${ }^{14-16}$

\section{Outcome}

Serum vitamin D was the study outcome, which was measured using an Enzymeimmunoassay by Uranus (AE 90) Auto Analyzer. The serum levels of 25-hydroxyvitamin D (unit: $\mathrm{nmol} / \mathrm{L}$ ) were assessed using ELISA (IDS 25-Hydroxy Vitamin D EIA kit, Immunodiagnostic Systems , UK). The intra-assay CV for 25-hydroxyvitamin D ranged from $4.6 \%$ to $8.7 \%$, and the interassay CV ranged from $5.3 \%$ to $6.7 \%$.

\section{Statistical analysis}

The normality for vitamin D was tested by the Shapiro-Wilk normality test in STATA. As we cannot reject the fact that vitamin D was normally distributed, data analysis was based on the original scale of vitamin D. Pearson $\chi^{2}$ test and one-way analysis of variance were used to compare baseline characteristics by smoking status. A multivariable general linear model was used to examine the crude and adjusted associations of smoking status with vitamin $\mathrm{D}$, from which the crude and adjusted regression coefficient and $95 \%$ CI were reported. Statistical analyses were performed using STATA/IC 10.1 (Stata Corp LP, College Station, Texas, USA).

\section{RESULTS}

Among 612 men, 270 (44\%) were never smokers, 154 (25\%) former smokers and $188(31 \%)$ were current smokers. Former smokers were older than current and never smokers, while current and never smokers were of similar age. Current smokers had lower education and prevalence of self-reported hypertension and cardiovascular disease, lower levels of body mass index and serum 
Table 1 Demographic characteristics of 612 older Chinese men

\begin{tabular}{|c|c|c|c|c|}
\hline & \multicolumn{3}{|l|}{ Smoking status } & \multirow[b]{2}{*}{ p Value } \\
\hline & Never $(n=270)$ & Former $(n=154)$ & Current $(n=188)$ & \\
\hline Age; mean (SD), year & $64.8(6.7)$ & $66.0(6.3)$ & $63.4(6.3)$ & 0.001 \\
\hline \multicolumn{5}{|l|}{ Education, \% } \\
\hline Primary or below & 15.7 & 24.7 & 33.0 & \multirow[t]{3}{*}{$<0.001$} \\
\hline Middle school & 59.3 & 66.2 & 55.9 & \\
\hline College or above & 25.0 & 9.1 & 11.1 & \\
\hline \multicolumn{5}{|l|}{ Physical activity, \% } \\
\hline Inactive & 5.6 & 5.2 & 13.3 & \multirow[t]{3}{*}{0.005} \\
\hline Moderate & 30.0 & 33.8 & 35.6 & \\
\hline Active & 64.4 & 61.0 & 51.1 & \\
\hline \multicolumn{5}{|l|}{ Alcohol use, \% } \\
\hline Never & 51.2 & 30.9 & 35.8 & \multirow[t]{2}{*}{$<0.001$} \\
\hline Ever & 48.8 & 69.1 & 64.2 & \\
\hline \multicolumn{5}{|l|}{ Self-reported diabetes, \% } \\
\hline No & 94.1 & 91.6 & 94.7 & \multirow[t]{2}{*}{0.46} \\
\hline Yes & 5.9 & 8.4 & 5.3 & \\
\hline \multicolumn{5}{|l|}{ Self-reported hypertension, \% } \\
\hline No & 72.0 & 66.9 & 78.9 & \multirow[t]{2}{*}{0.04} \\
\hline Yes & 28.0 & 33.1 & 21.1 & \\
\hline \multicolumn{5}{|l|}{ Self-reported cardiovascular disease, \% } \\
\hline No & 94.1 & 88.3 & 95.7 & \multirow[t]{2}{*}{0.02} \\
\hline Yes & 5.9 & 11.7 & 4.3 & \\
\hline \multicolumn{5}{|l|}{ Self-reported respiratory diseases, \% } \\
\hline No & 92.6 & 93.5 & 93.1 & \multirow[t]{2}{*}{0.94} \\
\hline Yes & 7.4 & 6.5 & 6.9 & \\
\hline Body mass index; mean (SD), kg/m² & $24.3(3.0)$ & $24.3(2.9)$ & $23.2(3.2)$ & $<0.001$ \\
\hline Waist circumference, mean (SD), cm & $85.8(9.1)$ & $86.3(9.0)$ & $85.0(8.8)$ & 0.39 \\
\hline 25-hydroxyvitamin D; mean (SD), nmol/L & $58.3(17.2)$ & $57.0(15.0)$ & $54.7(15.4)$ & 0.07 \\
\hline
\end{tabular}

vitamin $\mathrm{D}$ concentrations, and tended to be less physically active than never or former smokers (table 1 ).

Table 2 shows that, compared with never smokers, serum vitamin $\mathrm{D}$ concentration was lower in current smokers by -3.85 (95\% CI -7.1 to -0.59$) \mathrm{nmol} / \mathrm{L}$, adjusted for age, education, alcohol use, physical activity, body mass index and self-reported diabetes, hypertension, cardiovascular disease and respiratory disease. Compared to never smokers, current smokers had lower serum concentrations of vitamin $\mathrm{D}$, and the concentrations decreased with the increasing number of cigarettes per day $(-3.11(95 \%$ CI -9.05 to 2.82$),-3.29$ ( -8.3 to $1.72)$ and -4.61 ( -8.89 to -0.33$) \mathrm{nmol} / \mathrm{L}$ for $1-9,10-$ 19 and 20+cigarettes per day, respectively; $\mathrm{p}$ for trend $0.01)$, duration of smoking $(-1.39(-6.09$ to 3.30$)$ and $-5.39(-9.42$ to -1.35$) \mathrm{nmol} / \mathrm{L}$ for $1-39$ and $40+$ years, respectively; $\mathrm{p}$ for trend 0.008$)$ as well as pack-years $(-2.89(-6.78$ to 1.01$)$ and $-5.58(-10.48$ to -0.67$)$ $\mathrm{nmol} / \mathrm{L}$ for 1-39 and 40+pack-years, respectively; $\mathrm{p}$ for trend 0.009). Longer duration of quitting smoking was associated with higher vitamin $\mathrm{D}$ than was current smoking ( $p$ for trend 0.04). Analysis in current smokers showed that, compared to smokers with the lowest intensity of exposure (1-9 cigarettes per day; 1-39 years of duration and by pack-years), those with higher levels of exposure consistently showed lower levels of vitamin D, and the result was statistically significant in those with smoking duration of 40 years $(\beta-6.55,95 \%$ CI -12.09 to -1.01 ) (table 2).

\section{DISCUSSION}

Based on a community-based sample with natural exposure to vitamin $\mathrm{D}$, our study showed that current smoking was associated with lower serum concentrations of vitamin $\mathrm{D}$ than those of never smokers, and the association showed a dose-response pattern, with greater number of cigarettes per day, longer smoking duration and more pack-years being associated with lower vitamin D. Moreover, former smokers with a longer duration of quitting (20+ years) had higher vitamin D levels than did current smokers. Taking advantage of the current setting, where taking vitamin D supplements is rare $(<1 \%)$ and indoor smoking was common, our results of the negative association of smoking with vitamin $\mathrm{D}$ were less likely to be biased or confounded.

Our study is in line with several recent studies showing current smoking to be associated with vitamin $\mathrm{D}$ deficiency or lower serum vitamin D concentrations, ${ }^{4-8}$ 17-20 and provided complementary information on the doseresponse pattern. Recently, Soldin and colleagues found an adverse effect of smoking on the synthesis of steroid hormones, including vitamin D. ${ }^{21}$ The exact mechanisms 
Table 2 Crude and adjusted regression coefficient ( $\beta$-coefficient, 95\% $\mathrm{Cl}$ ) for serum vitamin $\mathrm{D}$ concentration (nmol/L) by cigarette smoking status in men

\begin{tabular}{|c|c|c|c|c|}
\hline & Number & $\begin{array}{l}\text { Crude } \beta \text {-coefficient } \\
(95 \% \mathrm{Cl})\end{array}$ & $\begin{array}{l}\text { Adjusted } \beta \text {-coefficient } \\
(95 \% \mathrm{Cl})\end{array}$ & $\begin{array}{l}\text { Adjusted } \beta \text {-coefficient } \\
(95 \% \mathrm{Cl})\end{array}$ \\
\hline \multicolumn{5}{|l|}{ Smoking status } \\
\hline Never & 270 & Reference $(0.00)$ & Reference $(0.00)$ & - \\
\hline Former & 154 & $-1.31(-4.5$ to 1.88$)$ & $-0.92(-4.29$ to 2.45$)$ & - \\
\hline Current & 188 & $-3.53(-6.53 \text { to }-0.53)^{*}$ & $-3.85(-7.1 \text { to }-0.59)^{\star}$ & - \\
\hline$P$ for trend & & 0.02 & 0.02 & - \\
\hline \multicolumn{5}{|c|}{ Amount of cigarette smoking per day $\dagger$} \\
\hline Never & 270 & Reference $(0.00)$ & Reference $(0.00)$ & - \\
\hline $1-9$ & 37 & $-2.88(-8.55$ to 2.8$)$ & $-3.11(-9.05$ to 2.82$)$ & Reference $(0.00)$ \\
\hline $10-19$ & 62 & $-2.69(-7.25$ to 1.87$)$ & $-3.29(-8.3$ to 1.72$)$ & $-0.54(-7.48$ to 6.41$)$ \\
\hline $20+$ & 89 & $-4.39(-8.34 \text { to }-0.43)^{\star *}$ & $-4.61(-8.89 \text { to }-0.33)^{*}$ & $-1.98(-8.44$ to 4.48$)$ \\
\hline$P$ for trend & & 0.01 & 0.01 & 0.50 \\
\hline \multicolumn{5}{|c|}{ Smoking duration (years)†‡ } \\
\hline Never & 270 & Reference $(0.00)$ & Reference $(0.00)$ & - \\
\hline $1-39$ & 77 & $-1.45(-5.64$ to 2.74$)$ & $-1.39(-6.09$ to 3.30$)$ & Reference $(0.00)$ \\
\hline $40+$ & 103 & $-5.05(-8.81 \text { to }-1.29)^{\star \star}$ & $-5.39(-9.42 \text { to }-1.35)^{\star \star}$ & $-6.55(-12.09 \text { to }-1.01)^{\star}$ \\
\hline$P$ for trend & & 0.01 & 0.008 & - \\
\hline \multicolumn{5}{|c|}{ Smoking status by pack-years $\dagger$} \\
\hline Never & 270 & Reference $(0.00)$ & Reference $(0.00)$ & - \\
\hline $1-39$ & 119 & $-2.79(-6.37$ to 0.78$)$ & $-2.89(-6.78$ to 1.01$)$ & Reference $(0.00)$ \\
\hline $40+$ & 61 & $-4.91(-9.52 \text { to }-0.30)^{\star *}$ & $-5.58(-10.48 \text { to }-0.67)^{\star}$ & $-3.95(-9.17$ to 1.27$)$ \\
\hline$P$ for trend & & 0.02 & 0.009 & - \\
\hline \multicolumn{5}{|c|}{ Duration of quitting (years)‡ } \\
\hline Current smokers & 188 & Reference $(0.00)$ & Reference $(0.00)$ & - \\
\hline $1-9$ & 50 & $-1.39(-6.11$ to 3.33$)$ & $-0.70(-5.74$ to 4.34$)$ & - \\
\hline $10-19$ & 50 & $2.22(-2.50$ to 6.94$)$ & $3.55(-1.57$ to 8.66$)$ & - \\
\hline $20+$ & 47 & $5.34(0.51 \text { to } 10.18)^{\star}$ & $4.66(-0.45$ to 9.77$)$ & - \\
\hline$P$ for trend & & 0.03 & 0.04 & - \\
\hline
\end{tabular}

Adjusted coefficient: adjusting for age, education, alcohol use, physical activity, body mass index and self-reported diabetes, hypertension, cardiovascular disease and respiratory disease.

${ }^{*} \mathrm{p}<0.05 ;{ }^{* *}: \mathrm{p}<0.01$.

†Excluding former smokers.

‡Eight current smokers with missing information on duration of smoking and seven former smokers with missing information on duration of quitting were excluded from data analysis here only.

by which smoking affects vitamin $\mathrm{D}$ metabolisms are still unclear. One possibility is that current smokers had a lower-vitamin D dietary pattern than never smokers, which may, partly, if at all, explain the negative association of smoking and vitamin D in our study. The other possible explanation is that chemicals in tobacco smoke may have a direct effect on vitamin D metabolism and function. ${ }^{17}$ Moreover, there is evidence that smoking may change the expression of some genes that play a role in the metabolic pathway of vitamin D. ${ }^{17} 22$

There are several limitations in the current study. First, this was a cross-sectional study. Whether smoking reduces vitamin $\mathrm{D}$ or if there is an association between smoking and vitamin D levels could not be confirmed due to residual confounding. Given the unquestionable harmful effects of tobacco smoke, it is unethical to conduct randomised controlled trials on smoking. Further interventional studies on animal models or Mendelian randomisation studies using genetic instruments as proxies of smoking ${ }^{23}$ may help to clarify the causal relation between smoking and serum vitamin
D. Second, information on sunlight exposure was not available in our study and thus could not be adjusted in the data analysis. However, we adjusted for physical activity, a proxy for sunlight exposure, in the regression model and the results did not change. Further studies taking into account average duration of sunlight exposure are warranted. Third, because very few Chinese women smoked, ${ }^{24}$ our results on men cannot be generalised to women, although there is no evidence suggesting that the effect of smoking on vitamin $\mathrm{D}$ varies by sex. Fourth, in older people, endogenous vitamin D synthesis were limited (lower skin concentrations of the vitamin D precursor, 7-Dehydrocholesterol) and dietary vitamin D could affect vitamin D status. The lack of detailed assessment of dietary vitamin $\mathrm{D}$ intake may be a concern. However, it is unlikely that dietary intake per se affects the smoking status-the underlying factors could be socioeconomic position (SEP). For example, people of lower SEP have more of a tendency to smoke than those of higher SEP and people of higher SEP tend to select foods rich in vitamin $\mathrm{D}$, such as milk. ${ }^{25}$ We have 
adjusted for education as a proxy of SEP in this study. Thus the potential confounding effect of dietary vitamin D intake due to SEP, if any, should not be a major concern. Fifth, the sample size of the current study was relatively small, particularly in detailed assessment of the linearity of smoking exposure and vitamin D. Finally, our participants were relatively healthy survivors and might not be fully representative of the general population. However, within sex and age group, the participants of the GBCS had fairly similar levels of chronic diseases such as diabetes and hypertension to those of nationally representative samples of urban Chinese. ${ }^{10}$ The strengths of this study include a detailed assessment of lifestyle and disease history, which may be associated with both smoking status and vitamin $\mathrm{D}$, and if ignored may lead to confounding bias.

In conclusion, current smoking had lower serum concentrations of vitamin D than never smoking, and the associations showed a dose-response pattern, with greater number of cigarettes per day, longer smoking duration and more pack-years being associated with lower vitamin D. Longer duration of quitting smoking was associated with higher vitamin D than was current smoking.

Contributors LX, CQJ, YHC, YLJ, TZ, WSZ, KKC and THL substantially contributed to conception and design, and acquisition and interpretation of data. CQJ, YHC and LX drafted the article and THL revised it critically for important intellectual content. All the authors contributed to final approval of the version to be published.

Funding Key technology collaboration project funded by the Bureau of Guangzhou Science and Technology (Grant number 2012J5100041; 2013J4100031).

Competing interests None declared.

Ethics approval The GBCS received approval from the Guangzhou Medical Ethics Committee of the Chinese Medical Association, and all participants gave written informed consent.

Provenance and peer review Not commissioned; externally peer reviewed.

Data sharing statement 0 wing to ethical restrictions protecting patient privacy, data only available on request from the GBCS Data Access Committee. Please contact us at gbcsdata@hku.hk.

Open Access This is an Open Access article distributed in accordance with the Creative Commons Attribution Non Commercial (CC BY-NC 4.0) license, which permits others to distribute, remix, adapt, build upon this work noncommercially, and license their derivative works on different terms, provided the original work is properly cited and the use is non-commercial. See: http:// creativecommons.org/licenses/by-nc/4.0/

\section{REFERENCES}

1. Bischoff-Ferrari HA, Willett WC, Wong JB, et al. Fracture prevention with vitamin $D$ supplementation: a meta-analysis of randomized controlled trials. JAMA 2005;293:2257-64.

2. Song Y, Wang L, Pittas AG, et al. Blood 25-hydroxy vitamin D levels and incident type 2 diabetes: a meta-analysis of prospective studies. Diabetes Care 2013;36:1422-8.
3. Elamin MB, Abu Elnour NO, Elamin KB, et al. Vitamin D and cardiovascular outcomes: a systematic review and meta-analysis. $J$ Clin Endocrinol Metab 2011;96:1931-42.

4. Shinkov A, Borissova AM, Dakovska L, et al. Winter 25-hydroxyvitamin $D$ levels in young urban adults are affected by smoking, body mass index and educational level. Eur J Clin Nutr 2015;69:355-60.

5. Kassi EN, Stavropoulos S, Kokkoris P, et al. Smoking is a significant determinant of low serum vitamin $D$ in young and middle-aged healthy males. Hormones (Athens) 2015;14:245-50.

6. Colao A, Muscogiuri G, Rubino M, et al. Hypovitaminosis D in adolescents living in the land of sun is correlated with incorrect lifestyle: a survey study in Campania region. Endocrine 2015;49:521-7.

7. Lange NE, Sparrow D, Vokonas $P$, et al. Vitamin D deficiency, smoking, and lung function in the Normative Ageing Study. Am J Respir Crit Care Med 2012;186:616-21.

8. Cutillas-Marco E, Fuertes-Prosper A, Grant WB, et al. Vitamin D deficiency in South Europe: effect of smoking and ageing. Photodermatol Photoimmunol Photomed 2012;28:159-61.

9. Grimnes $\mathrm{G}$, Almaas B, Eggen AE, et al. Effect of smoking on the serum levels of 25-hydroxyvitamin $D$ depends on the assay employed. Eur J Endocrinol 2010;163:339-48.

10. Jiang C, Thomas GN, Lam TH, et al. Cohort profile: the Guangzhou Biobank Cohort Study, a Guangzhou-Hong Kong-Birmingham collaboration. Int J Epidemiol 2006;35:844-52.

11. Xu L, Jiang CQ, Schooling CM, et al. Prediction of 4-year incident diabetes in older Chinese: recalibration of the Framingham diabetes score on Guangzhou Biobank Cohort Study. Prev Med 2014;69:63-8.

12. $\mathrm{Xu} \mathrm{L}$, Jiang $\mathrm{CQ}$, Lam $\mathrm{TH}$, et al. Sleep duration and memory in the elderly Chinese: Iongitudinal analysis of the Guangzhou Biobank Cohort Study. Sleep 2014;37:1737-44.

13. Deng HB, Macfarlane DJ, Thomas GN, et al. Reliability and validity of the IPAQ-Chinese: the Guangzhou Biobank Cohort study. Med Sci Sports Exerc 2008:40:303-7.

14. Jiang CQ, Lao XQ, Yin P, et al. Smoking, smoking cessation and aortic arch calcification in older Chinese: the Guangzhou Biobank Cohort Study. Atherosclerosis 2009;202:529-34.

15. Jiang CQ, Xu L, Lam TH, et al. Smoking cessation and carotid atherosclerosis: the Guangzhou Biobank Cohort Study-CVD. $J$ Epidemiol Community Health 2010;64:1004-9.

16. Lam KB, Jiang CQ, Jordan RE, et al. Prior TB, smoking, and airflow obstruction: a cross-sectional analysis of the Guangzhou Biobank Cohort Study. Chest 2010;137:593-600.

17. Brot $\mathrm{C}$, Jorgensen NR, Sorensen $\mathrm{OH}$. The influence of smoking on vitamin D status and calcium metabolism. Eur J Clin Nutr 1999;53:920-6.

18. Supervía A, Nogués $X$, Enjuanes $A$, et al. Effect of smoking and smoking cessation on bone mass, bone remodeling, vitamin D, PTH and sex hormones. J Musculoskelet Neuronal Interact 2006;6:234-41.

19. Shi L, Nechuta S, Gao YT, et al. Correlates of 25-Hydroxyvitamin D among Chinese breast cancer patients. PLoS ONE 2014;9:e86467.

20. Kühn T, Kaaks R, Teucher B, et al. Dietary, lifestyle, and genetic determinants of vitamin $D$ status: a cross-sectional analysis from the European Prospective Investigation into Cancer and Nutrition (EPIC)-Germany study. Eur J Nutr 2014;53:731-41.

21. Soldin OP, Makambi KH, Soldin SJ, et al. Steroid hormone levels associated with passive and active smoking. Steroids 2011;76:653-9.

22. O'Shaughnessy PJ, Monteiro A, Bhattacharya S, et al. Maternal smoking and fetal sex significantly affect metabolic enzyme expression in the human fetal liver. J Clin Endocrinol Metab 2011;96:2851-60.

23. Åsvold $\mathrm{BO}$, Bjørngaard $\mathrm{JH}$, Carslake $\mathrm{D}$, et al. Causal associations of tobacco smoking with cardiovascular risk factors: a Mendelian randomization analysis of the HUNT Study in Norway. Int $J$ Epidemiol 2014;43:1458-70.

24. Li Q, Hsia J, Yang G. Prevalence of smoking in China in 2010. N Engl J Med 2011;364:2469-70.

25. Sun $\mathrm{Y}$, Jiang $\mathrm{C}$, Cheng KK, et al. Milk consumption and cardiovascular risk factors in older Chinese: the Guangzhou Biobank Cohort Study. PLoS One 2014;9:e84813. 